\title{
Geldanamycin destabilizes HER2 tyrosine kinase and suppresses Wnt/B-catenin signaling in HER2 overexpressing human breast cancer cells
}

\author{
KE WANG ${ }^{1}$, QINGYONG MA ${ }^{2}$, YU REN ${ }^{1}$, JIANJUN HE ${ }^{1}$, \\ YONG ZHANG $^{1}$, YUNFENG ZHANG ${ }^{1}$ and WUKE CHEN ${ }^{1}$ \\ Departments of ${ }^{1}$ Surgical Oncology and ${ }^{2}$ Hepatobiliary Surgery, First Hospital \\ of Xi'an Jiaotong University, Xi'an 710061, P.R. China
}

Received July 18, 2006; Accepted September 19, 2006

\begin{abstract}
HER2 (also known as ErbB2) is a transmembrane tyrosine kinase whose surface overexpression is linked to tumorigenesis and poor prognosis in breast cancer patients. B-catenin is a substrate of this kinase, and HER2-dependent phosphorylation of tyrosine 654 leads to dissociation of the E-cadherin- $\beta$-catenin membrane complex and increased Wnt signaling. B-catenin-mediated Wnt signaling promotes proliferation and invasion of breast cancer cells. In this study, we show that HER2 binds to $\beta$-catenin and that geldanamycin (GA), a drug that destabilizes HER2 protein, causes rapid depletion of HER2, thereby disrupting its association with B-catenin in SKBr3 human breast cancer cells. Interestingly, GA did not affect the stability of B-catenin protein, but altered its subcellular localization, driving it out of the nucleus and increasing its association with E-cadherin. Importantly, the change in subcellular localization of $\beta$-catenin was also associated with a significant decrease in proliferation and motility of GA-treated breast cancer cells. Moreover, GA treatment led to reduced expression of the Wnt signaling target and cell cycle-promoting gene cyclin D1, providing a potential mechanism for the reduced proliferation. In conclusion, GA treatment suppressed tumorigenicity in the human breast cancer cell line SKBr3, at least in part through destabilization of the HER2 oncoprotein and repression of the $\mathrm{Wnt} / \mathrm{B}$-catenin signaling pathway. These findings provide evidence for the clinical importance of GA in treatment of HER2 overexpressing breast cancers.
\end{abstract}

Correspondence to: Dr Qingyong Ma, Department of Hepatobiliary Surgery, First Hospital of Xi'an Jiaotong University, 1 Jiankang Road, Xi'an 710061, P.R. China

E-mail: xjtu_wet@163.com

Abbreviations: HER2, human epidermal growth factor receptor 2; GA, geldanamycin

Key words: HER2, GA, B-catenin, Wnt, breast cancer

\section{Introduction}

HER2 is a member of the epidermal growth factor receptor (EGFR) family that is overexpressed in about $25-30 \%$ of breast cancers and, to a lesser degree, in other cancers (1). Survival and time to relapse are shorter in patients whose tumor cells overexpress HER2 (2,3). HER2 overexpression has been shown to enhance proliferation, survival, and possibly metastatic potential (4). Interestingly, HER2 activation in melanoma cells has recently been found to be associated with dysregulation of $ß$-catenin, a central member of the Wnt signaling pathway (5).

ß-catenin was originally identified as a component of cellcell adhesion complexes containing E-cadherin, B-catenin, $\alpha$-catenin and actin. It has become clear during the past decade that $B$-catenin also controls transcription, in concert with TCF/ LEF proteins, of Wnt target genes including cyclin D1 and $c-M y c(6,7)$. In normal epithelial cells, B-catenin associates with the cytoplasmic domain of E-cadherin, linking this transmembrane adhesion molecule to the actin cytoskeleton via $\alpha$-catenin. Recently, several researchers have reported that HER2 can interact with the carboxyl terminus of $B$-catenin near tyrosine-654 (Tyr-654) (8), and the Tyr-654 residue of $\beta$-catenin is preferentially phosphorylated under conditions that disrupt $\beta$-catenin-E-cadherin association (9). Thus, the phosphorylation status of Tyr-654, a HER2-binding domain, regulates $\beta$-catenin association with E-cadherin. When released from E-cadherin, uncomplexed B-catenin is rapidly degraded by cytosolic ubiquitin-dependent proteasomes. However, mutation of certain Wnt signaling pathway components can lead to accumulation of uncomplexed B-catenin that can translocate to the nucleus where it can activate transcription of a number of proliferation-promoting genes (7). Nuclear accumulation of $\beta$-catenin is thus thought to play a pivotal role in tumor progression, and may at least partially explain the tumorigenicity of HER2 overexpressing breast cancer cells.

The antibiotic benzoquinone ansamycin (GA) is a novel anticancer agent that inhibits the molecular chaperone Heat shock protein 90 (Hsp90) by occupying its NH2-terminal ATP-binding site $(10,11)$. The GA derivative, 17-allylaminogeldanamycin (17AGG), is now in Phase I clinical trial at several centers worldwide (12). Previous studies have shown 
that GA-mediated degradation of HER2 protein can prevent proliferation and invasion of HER 2 overexpressing breast cancer cells via several signaling pathways, including AKT and PI3K (13). However, the role of Wnt signaling in HER2 overexpressing breast cancer cells has been only slightly investigated. The human breast cancer cell line SKBr3, which overexpresses HER2, also exhibits aberrant activation of the Wnt signaling pathway (14). In this study, we show that the antitumor activity of GA can be explained by degradation of HER 2 and repression of the Wnt signaling pathway, using $\mathrm{SKBr} 3$, a human breast cancer cell line.

\section{Materials and methods}

Cell culture. The human breast cancer cell line SKBr3 was obtained from American Type Culture Collection and maintained in 1:1 mixture of DMEM and F12 media, supplemented with $3 \mathrm{mM}$ glutamine, $50 \mathrm{U} / \mathrm{ml}$ penicillin, $50 \mathrm{U} / \mathrm{ml}$ streptomycin and $10 \%$ heat-inactivated fetal bovine serum (Hyclone).

Reagents. GA (Sigma) in DMSO (Sigma) (5 mM) was diluted in culture medium to final concentrations of 5, 10 and $20 \mathrm{nM}$, with final DMSO concentrations not exceeding 0.01\%. Antibodies used for immunoprecipitation and immunoblotting studies were as follows: anti-HER2, anti-E-cadherin, anti- $\beta$ actin (all from Santa Cruz), anti-ß-catenin (Neomarker), and HRP-conjugated goat anti-rabbit (Pierce). All other reagents were from Sigma, unless otherwise specified.

Cell proliferation test by MTT reduction. The cytotoxicity on SKBr3 cell proliferation was quantified by measurement of the reduction of MTT(3-(4,5-dimethylthiazol-z-yl)-2,5-diphenyl tetrazolium bromide) to produce a dark blue formazan product. Cells in the exponential phase of growth were harvested and seeded in 96-well plates (Costar) at a density of $1 \times 10^{4}$ cells per well. After $24 \mathrm{~h}$, drugs were added to triplicate wells for each concentration $(0,5,10$ and $20 \mathrm{nM})$ and incubation for 24 and $48 \mathrm{~h}$, then MTT was added to each well and the plate was incubated at $37^{\circ} \mathrm{C}$ in a $\mathrm{CO}_{2}$ incubator. After 4-h incubation, the medium was removed, and $150 \mu 1 \mathrm{DMSO}$ was added to each well to dissolve the formazan crystals and optical density (OD) was measured at a wavelength of $570 \mathrm{~nm}$ using a microplate reader (Multiskan MK3). The production of formazan crystals, and therefore the intensity of color after their dissolution, is proportional to the number of viable cells. Proportions of viable cells in the treatment groups were calculated relative to the controls $(100 \%) . \mathrm{IC}_{50}$ is calculated as the drug concentration that inhibits cell growth by $50 \%$ compared with control growth.

Immunoprecipitation and immunoblotting. Cells were grown to $60-70 \%$ confluence and exposed to drug or DMSO for the indicated time periods. Cells were washed twice with icecold PBS and incubated $30 \mathrm{~min}$ in ice-cold lysis buffer $(20 \mathrm{mM}$ Tris- $\mathrm{HCl} \mathrm{pH} 8.0,1 \%$ Triton $\mathrm{X}-100,140 \mathrm{mM} \mathrm{NaCl}, 10 \%$ glycerol, $1 \mathrm{mM}$ EGTA, $1.5 \mathrm{mM} \mathrm{MgCl}_{2}, 1 \mathrm{mM}$ DTT, $1 \mathrm{mM}$ sodium vanadate, $50 \mathrm{mM} \mathrm{NaF}, 50 \mathrm{mM}$, and complete protease inhibitors (Roche, one tablet complete protease inhibitor cocktail in $50 \mathrm{ml}$ lysis buffer), then scraped, collected, and clarified by centrifugation ( $14000 \mathrm{x} \mathrm{g}$ for $15 \mathrm{~min}$ at $\left.4^{\circ} \mathrm{C}\right)$. Protein concentrations were determined using a BCA kit (Pierce), according to the manufacturer's instructions. Immunoprecipitations and immunoblotting were performed as described (15), using the Super Signal chemiluminescent substrate (Pierce). Films were scanned, and bands were quantified using image analysis software (NIH Image).

To analyze $\beta$-catenin in nuclear fractions, intact nuclei were prepared from exponentially growing cells by using NE-PER nuclear and cytoplasmic extraction reagents (Pierce) according to manufacture's instructions, and complete protease inhibitors (Roche) was added to the reagents. Nuclear extracts of these samples were fractionated by $8 \%$ SDS-PAGE, electrotransferred to nitrocellulose membranes, and analyzed for ß-catenin by Western blotting.

RT-PCR and real-time PCR. Cells $\left(2 \times 10^{6}\right)$ were harvested, washed, and total-RNA was isolated using TRIzol reagent (Invitrogen) following the manufacturer's protocol. cDNA was synthesized from isolated RNA using the RevertAid ${ }^{\text {TM }}$ first strand cDNA synthesis kit (Fermentas). Primers used for cyclin D1 were: AATGACCCCGCACGATTTC and TCAG GTTCAGGCCTTGCAC. The $\beta_{2}$-microglobulin gene was used as an internal control. Primers used for $\beta_{2}$-microglobulin were: GAGTATGCCTGCCGTGTG and AATCCAAATGCGGCA TCT. RT-PCR was performed using $1 \mu \mathrm{g}$ template, $2 \mu \mathrm{l}$ of 1X PCR buffer (Takara), $1.6 \mu 1$ of dNTP mixture (Takara), $0.4 \mu \mathrm{M}$ of each primer and $0.5 \mathrm{U}$ of Takara Taq (Takara) in a final volume of $20 \mu \mathrm{l}$. PCR conditions were as follows: $95^{\circ} \mathrm{C}$ for $5 \mathrm{~min}, 35$ cycles: $94^{\circ} \mathrm{C}$ for $20 \mathrm{sec}, 60^{\circ} \mathrm{C}$ for $45 \mathrm{sec}, 1 \mathrm{~min}$ at $72^{\circ} \mathrm{C}$, then followed by $10 \mathrm{~min}$ of a final extension step at $72^{\circ} \mathrm{C}$. PCR products (190 and $109 \mathrm{bp}$, respectively) were analyzed by electrophoresis on a $3 \%$ agarose gel. Real-time PCR was performed using the ABI PRISM 7000 SDS thermal cycler and SYBRE Green I Mix (Takara) following the manufacturer's protocol, using the following conditions: 1 cycle at $95^{\circ} \mathrm{C}$ for $3 \mathrm{~min}, 45$ cycles at $95^{\circ} \mathrm{C}$ for $20 \mathrm{sec}, 60^{\circ} \mathrm{C}$ for $30 \mathrm{sec}$ and $72^{\circ} \mathrm{C}$ for $30 \mathrm{sec}$ where fluorescence was measured, this cycling was followed by melting curve analysis to distinguish specificity of the PCR products. Measurements were normalized against $\beta_{2}$-microglobulin levels.

Flow cytometric cell cycle analysis. Cell cycle distribution was assayed according to Nusse et al (16) using a BectonDickinson fluorescence-activated cell scanner and analyzed using the CellCycle Multi-cycle System (Phoenix Flow System).

Motility assay. Approximately $5 \times 10^{4}$ cells were seeded onto cell culture inserts ( $8 \mu \mathrm{m}$ pore size, Falcon 3097) in 24-well plates containing $0.7 \mathrm{ml}$ medium. Cells were incubated for 24 or $48 \mathrm{~h}$ with increasing concentrations of $\mathrm{GA}(0,5,10$ and $20 \mathrm{nM}$ ). After GA treatment, the number of cells adhering to the bottom of the well was counted. Motility was defined as the number of adherent cells after GA treatment relative to control, untreated wells. Bound cells were identified for counting by Wright stain.

Statistical analysis. Statistical analyses were performed using SPSS 12.0 for Windows, and the Student's t-test was used to 

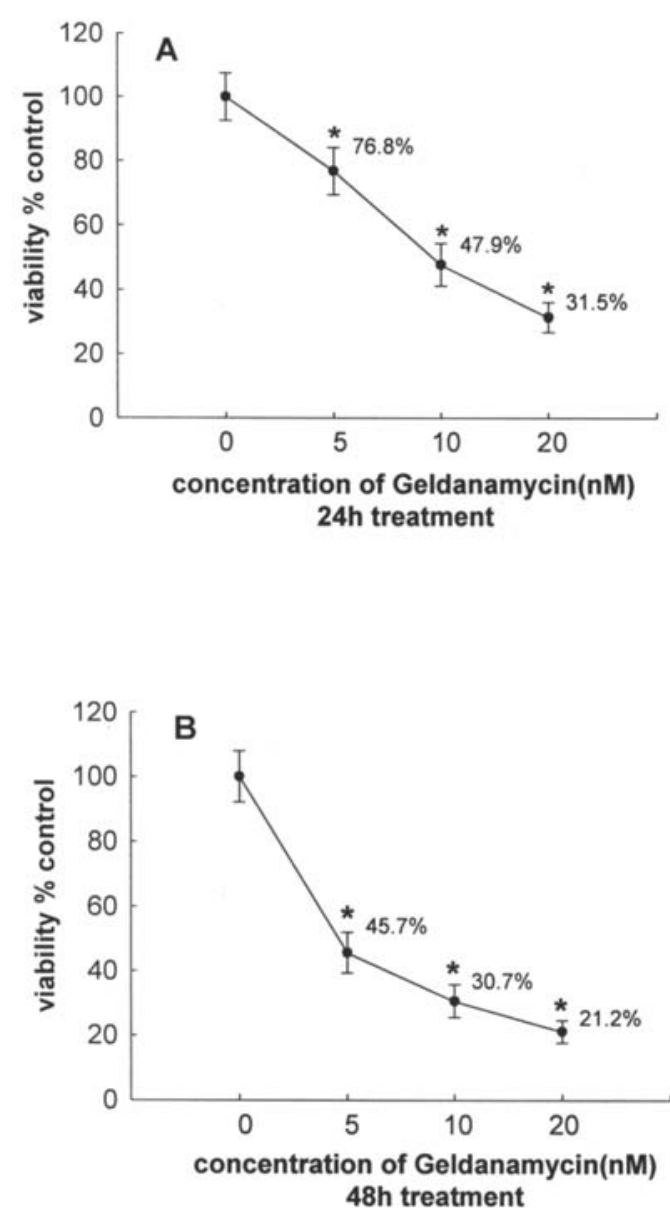

C

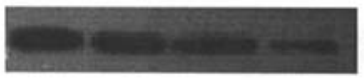

$0 \quad 5 \quad 10$

IB: HER2-24h

20
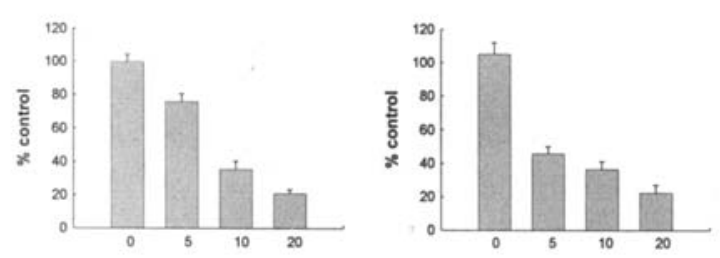

Figure 1. Effect of GA on the viability of SKBr3 cells cultured in vitro for 24 and $48 \mathrm{~h}$, and viable cell numbers was determined by MTT assay. Proliferation was evaluated by calculating percentage of viable cells in the treatment groups relative to the controls $(100 \%)$. Data are the means \pm SD. $\mathrm{n}=3,{ }^{*} \mathrm{P}<0.05$. Bars, SD. GA inhibited proliferation of SKBr3 cells in a dosedependent fashion, after $24 \mathrm{~h} \mathrm{(A)}$ and $48 \mathrm{~h}(\mathrm{~B})$ treatment. The $\mathrm{IC}_{50}$ for each treatment is 9.6 and $4.3 \mathrm{nM}$, respectively $(\mathrm{n}=3)$. (C), Immunoblot comparison of HER2 protein expression in cells 24 and $48 \mathrm{~h}$ after GA treatment. GA induces a dose-dependent degradation of the HER2 tyrosine kinase $(n=3)$. Bars, SD.

compare the differences between treatments and controls. $\mathrm{P}<0.05$ was considered to be statistically significant. All other data are presented as mean $\pm \mathrm{SD}$.

\section{Results}

The anti-proliferative effects of GA treatment correlate with HER2 levels. GA causes degradation of several signaling proteins. The HER family of kinases are particularly sensitive to GA-induced degradation, especially HER2 (17). We assessed whether cells that overexpress HER2 are sensitive to GA treatment. We treated the breast cancer cell line SKBr3, which expresses high levels of HER2 protein, with increasing concentrations of GA for 24 and $48 \mathrm{~h}$ and evaluated the effects on cell proliferation which was assessed using the MTT assay (18). The concentrations that elicited $50 \%$ inhibition of proliferation $\left(\mathrm{IC}_{50}\right)$ after $\mathrm{GA}$ exposure were determined. After $24 \mathrm{~h}$ of GA treatment, cell proliferation was inhibited in a dosedependent fashion with an $\mathrm{IC}_{50}$ value of $9.6 \mathrm{nM}$ (Fig. 1A). Interestingly, after $48 \mathrm{~h}$ of treatment, GA continued to repress cell proliferation in a dose-dependent manner, but the $\mathrm{IC}_{50}$ value decreased to $4.3 \mathrm{nM}$ (Fig. 1B), and $5 \mathrm{nM}$ GA repressed proliferation more after $48 \mathrm{~h}$ than after $24 \mathrm{~h}$. These results indicate that while $10 \mathrm{nM}$ GA can repress the proliferation of more than $50 \%$ of HER2-overexpressing cells, 5 nM GA can repress an equivalent number of cells after $48 \mathrm{~h}$ of treatment.

Protein expression levels for HER2 were evaluated by Western blot. As expected, GA induced a dose-dependent degradation of the HER2 tyrosine kinase (Fig. 1C). Densitometric analysis revealed that $>70 \%$ of HER 2 protein, relative to control, had been degraded by $24 \mathrm{~h}$ of treatment with $20 \mathrm{nM}$ GA. However, $5 \mathrm{nM}$ GA required a longer incubation time to destablize HER2 protein efficiently, consistent with the effects of this dose on cell proliferation.

GA treatment suppresses aberrant activation of the Wnt/ $\beta$-catenin signaling pathway and increases binding between $\beta$-catenin and E-cadherin. Previous studies have demonstrated a functional relationship between $\beta$-catenin and HER2 tyrosine kinase in tumor progression $(5,19)$. B-catenin is a substrate of the HER2 tyrosine kinase. Phosphorylation of Tyr-654 of ß-catenin by HER2 leads to dissociation of the E-cadherin$\beta$-catenin adhesion complex and activation of the Wnt signaling pathway $(5,19)$. We therefore examined whether the interaction between HER 2 and $\beta$-catenin could be detected in $\mathrm{SKBr} 3$ breast cancer cells. Cells were lysed in lysis buffer and immunoprecipitated with an antibody specific for HER2, then examined by SDS-PAGE and immunoblotting using a ß-catenin-specific antibody (Fig. 2A). The results demonstrated the existence of an interaction between HER2 and B-catenin in SKBr3 breast cancer cells, suggesting that GA-mediated degradation of HER 2 could abrogate this interaction.

Translocation of $\beta$-catenin from the membrane to the nucleus leads to activation of the Wnt pathway (20). We next asked whether the disruption of function interaction between HER 2 and $B$-catenin, mediated by GA, could change subcellular location of B-catenin and thus influence the Wnt signaling pathway in SKBr3 cells. After GA treatment, total$\beta$-catenin levels were unchanged, relative to $\beta$-catenin levels in untreated cells (Fig. 2B). However, the level of nuclear $\beta$-catenin decreased markedly following GA treatment (Fig. 2C). This result suggests that $ß$-catenin is transported from the nucleus to the cytoplasm and/or membrane as a consequence of GA treatment, and possibly HER2 degradation. Two lines of evidence suggest that the change in subcellular localization of $\beta$-catenin may be due directly to degradation of HER2. First, the change in subcellular localization of B-catenin appears to follow a similar dose-response curve as the degradation of HER2 protein. Second, GA treatment disrupted 
A
IP:

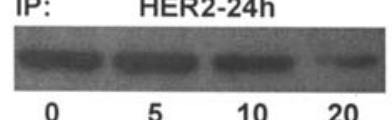

IB: $\quad \beta$-Catenin-24h

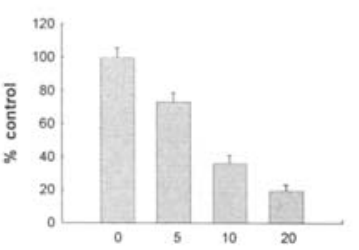

B
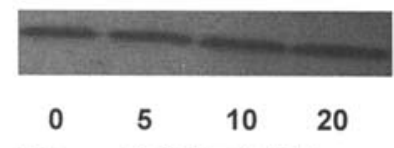

IB: $\quad \beta$-Catenin-24h

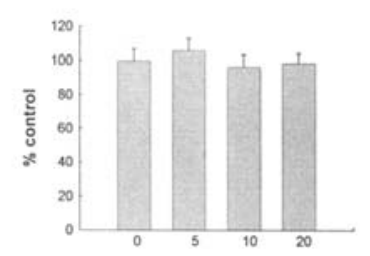

C
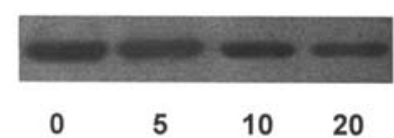

NIB: $\quad \beta$-Catenin-24h

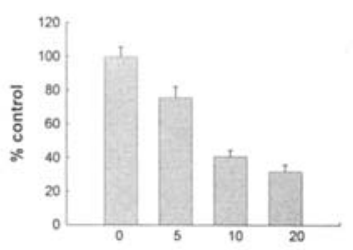

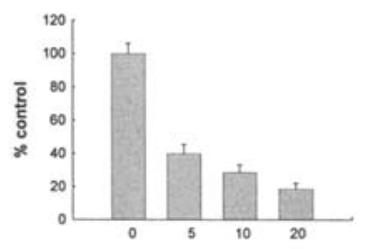
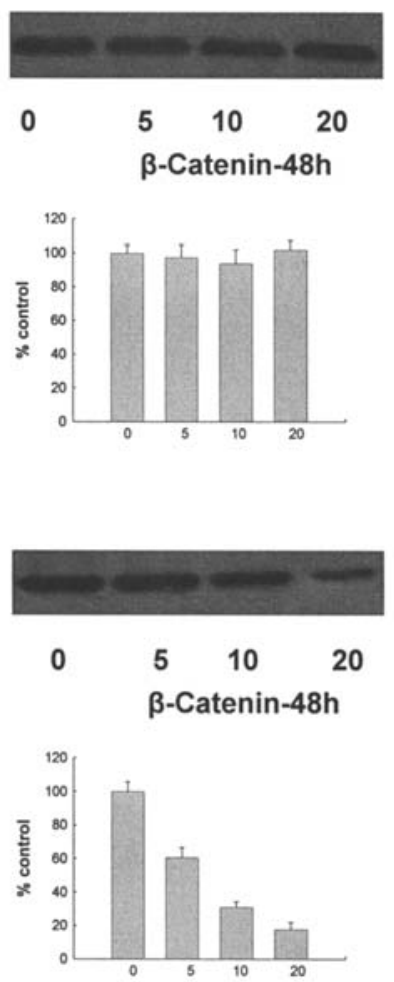

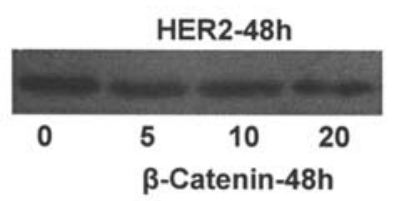

binding between HER2 and ß-catenin, leading to nuclear export of $\beta$-catenin, consistent with reduced Wnt signaling. Our results are therefore consistent with a model in which GA treatment of SKBr3 breast cancer cells leads to degradation of HER2 and repression of the Wnt signaling pathway.

In normal breast epithelial cells, $\beta$-catenin associates with the cytoplasmic domain of E-cadherin, near the plasma membrane, and this association is critically important for the maintenance of tight cell-cell contacts (21). To investigate whether the nuclear export of $\beta$-catenin enhances its association with E-cadherin, we next examined the amount of $\beta$-catenin associated with E-cadherin before and after GA treatment. Cell lysates were immunoprecipitated with an antibody specific for E-cadherin and examined by immunoblotting using a B-catenin-specific antibody and densitometry (Fig. 2D). As expected, the amount of $\beta$-catenin coimmunoprecipitated with E-cadherin increased in proportion to the amount that nuclear B-catenin decreased in GA-treated samples, while total-Ecadherin levels remained unchanged (Fig. 2E). Interestingly, in untreated samples, some $\beta$-catenin still remained associated with E-cadherin. These data suggest that not all $\beta$-catenin is
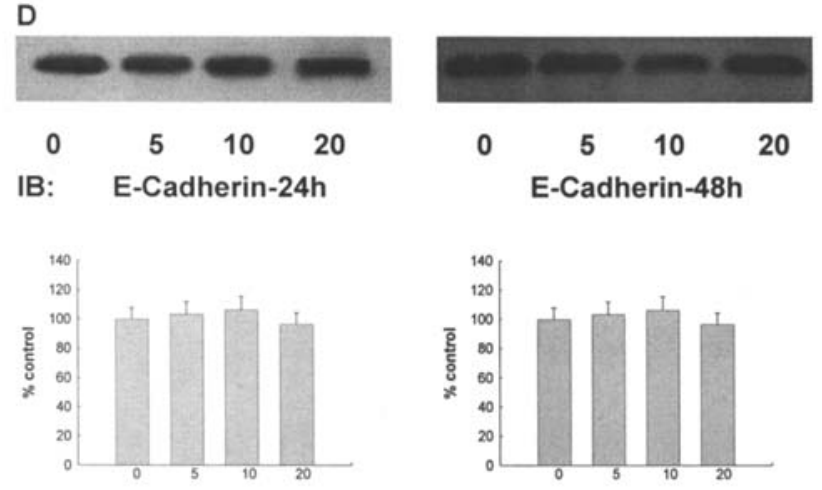

E
IP: E-Cadherin-24h

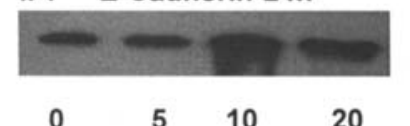

IB: $\quad \beta$-Catenin-24h

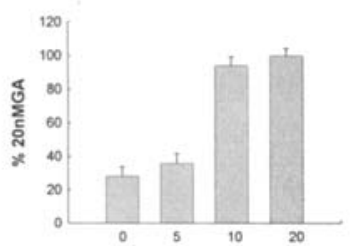

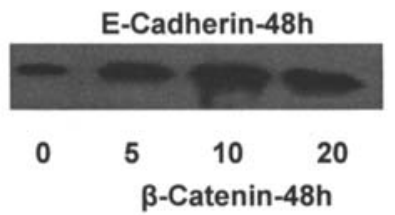

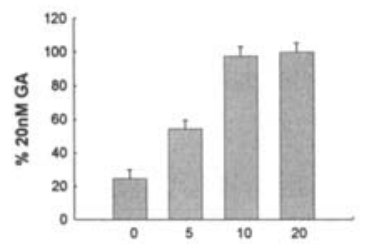

Figure 2. Exponentially growing $\mathrm{SKBr} 3$ breast cancer cells were cultured for 24 or $48 \mathrm{~h}$ in the presence of 5, 10 and $20 \mathrm{nM} \mathrm{GA}$. Cells were then incubated in ice-cold lysis buffer and cell lysates were probed with immunoprecipitation and immunoblotting $(\mathrm{n}=3)$. (A), Cell lysates were immunoprecipitated with an antibody specific for HER2. After SDS-PAGE, all immunoblots were probed with a B-catenin-specific antibody. HER2 and B-catenin can be coimmunoprecipitated before GA treatment. With degradation of HER2 protein mediated by various concentrations of GA, HER2 association with B-catenin decreased gradually. (B), After exposure to GA, the total-B-catenin of immunoblots remains at steady-state level. (C), Nuclear lysates were separated as described in Materials and methods to detect nuclear $\beta$-catenin by immunoblotting using anti- $\beta$-catenin antibody. The level of nuclear B-catenin declined markedly after efficient GA treatment. (D), After GA treatment, cell lysates were immunoprecipitated with an antibody specific for E-cadherin. After SDS-PAGE, all immunoblots were probed with a $\beta$-catenin-specific antibody. GA treatment increased association between E-cadherin and B-catenin. (E), Total-Ecadherin level of immunoblots was not affected by GA treatment. Bars, SD.

nuclear in SKBr3 breast cancer cells, and that B-catenin therefore plays a dual-role in this cell line.

$G A$ treatment inhibits $\beta$-catenin-dependent transcription in $\mathrm{SKBr} 3$ breast cancer cells. Because GA treatment led export of nuclear $\beta$-catenin, we next asked whether $\beta$-catenindependent transcription was repressed following GA treatment. We therefore monitored the effects of GA on the expression of the B-catenin target gene cyclin D1, with and without GA treatment, by RT-PCR and real-time PCR. GA treatment inhibited cyclin D1 expression in a dose-dependent manner, and in a manner that correlated with levels of nuclear B-catenin (Figs. 3 and 2C). Thus GA inhibited transcription of cyclin D1, a target of $\beta$-catenin-dependent Wnt signaling. Since cyclin D1 

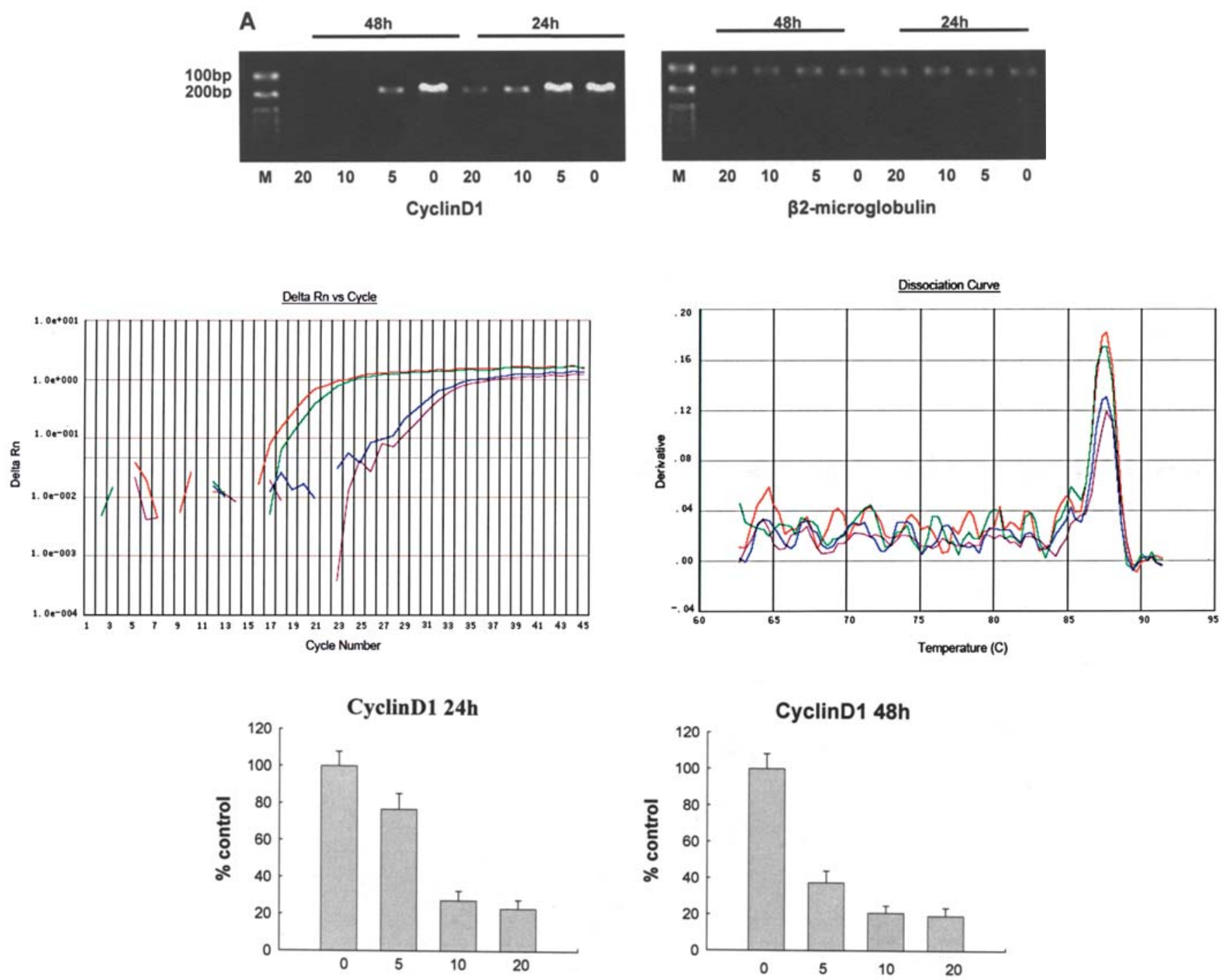

Figure 3. RT-PCR (A) and real-time PCR (B) analysis of cyclin D1 mRNA and $\beta_{2}$-microglobulin mRNA after GA treatment (nM). GA markedly reduced transcription of cyclin D1 in a dose-dependent manner (n=3). Bars, SD. (M, markers; PCR products of cyclin D1 and $\beta_{2}$-microglobulin was 190 and 109 bp, respectively).

is an important cell cycle gene, GA-induced reduction of cyclin DI levels is consistent with the anti-proliferative effects mentioned above.

GA treatment arrests SKBr3 breast cancer cells in the G1 phase of the cell cycle. G1 cell cycle arrest in response to GA treatment has been observed in cell lines that express the Retinoblastoma $(\mathrm{Rb})$ oncoprotein, while cells lacking $\mathrm{Rb}$ arrest in the G2/M phase of the cell cycle (22). Since SKBr3 is an $\mathrm{Rb}$-positive breast cancer cell line (23), we next asked whether GA treatment led to G1 cell cycle arrest using flow cytometric analysis. We found that GA treatment arrested SKBr3 cells in the G1 phase of the cell cycle (Fig. 4). These observations are consistent with reduced levels of cyclin DI following GA treatment (Fig. 3) because cyclin D1 is an essential G1 cyclin, involved in regulating the G1-S transition. These data suggest a mechanism whereby HER2 could regulate cell cycle progression by phosphorylating and stabilizing nuclear $\beta$-catenin, increasing cyclin $D 1$ transcription in cancerous cells. However, in GA-treated cells, HER2 protein is destabilized, leading to increased exit of nuclear B-catenin, decreased cyclin DI transcription, and G1 cell cycle arrest.

GA treatment inhibits $S K B r 3$ cell motility. Because the abundance of membrane-associated B-catenin-E-cadherin complexes is inversely related to cell motility (24), we wished to determine whether GA treatment could reduce the motility of SKBr3 breast cancer cells in vitro. Interestingly, when added to a 24-h in vitro motility assay, $20 \mathrm{nM} \mathrm{GA}$ almost completely abolished motility of SKBr3 cells (Fig. 5). These results are consistent with the observed increase in association of $\beta$-catenin and E-cadherin following GA treatment.

\section{Discussion}

The HER2 oncogene encodes a $185-\mathrm{kDa}$ EGFR-like transmembrane glycoprotein with tyrosine kinase activity. This oncogene is overexpressed in approximately $15-30 \%$ of breast 
A
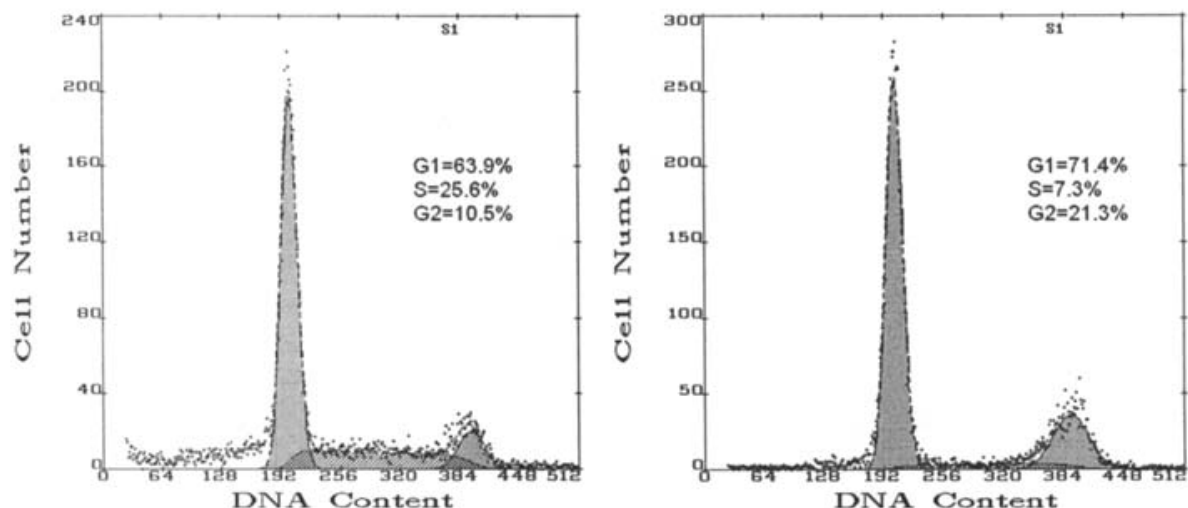

B
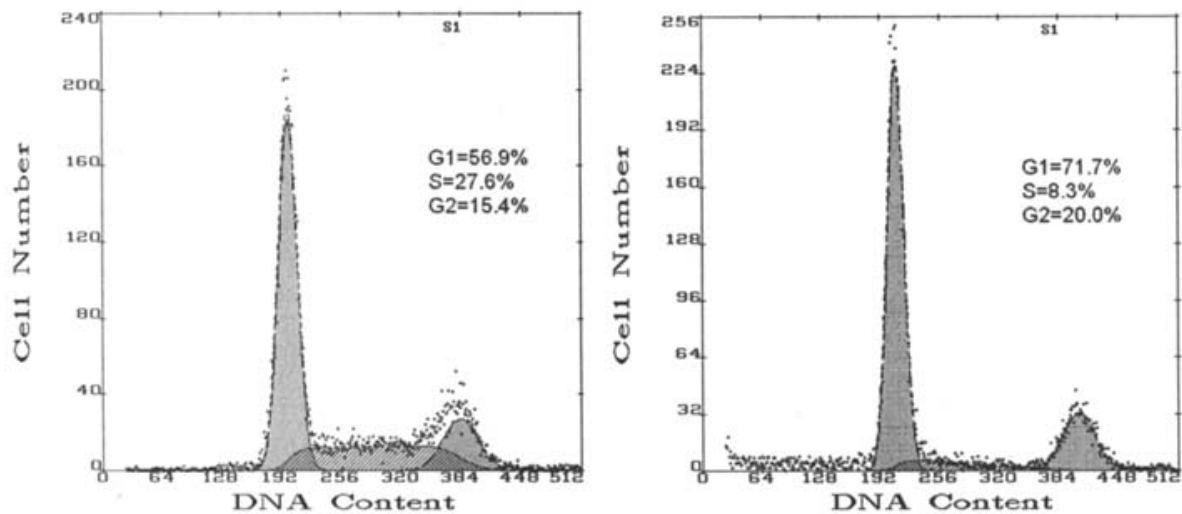

Figure 4. Cell cycle analysis by flow cytometry. The percentage of cells in G1, S and G2 phase is indicated (A) at $24 \mathrm{~h}$ and (B) $48 \mathrm{~h}$. GA (5, 10 and $20 \mathrm{nM}$ ) treatment causes a dose-dependent G1 block. (A), Before GA treatment, percentage of S phase is $25.6 \%$; after 24-h treatment of $20 \mathrm{nM}$ GA it decreased to $7.3 \%$. (B), Similarly, 48 -h treatment of $20 \mathrm{nM} \mathrm{GA}$ decreased percentage of S phase from 27.6 to $8.3 \%$.
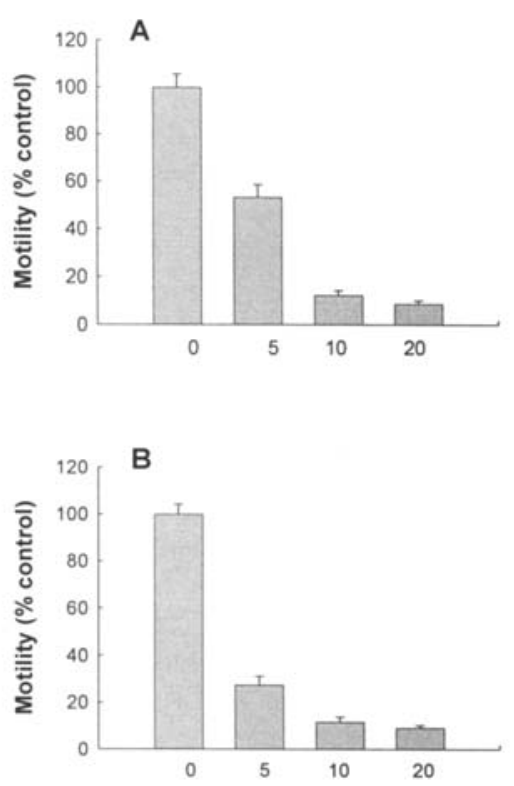

Figure 5. SKBr3 cell motility. GA (nM) markedly reduced the motility of $\mathrm{SKBr} 3$ cells $(\mathrm{n}=3)$. (A), Motility of $\mathrm{SKBr} 3$ cells decreased to $53.3,12.4$ and $8.8 \%$ after $24 \mathrm{~h}$ of GA treatment $(5,10$ and $20 \mathrm{nM})$. (B), After $48 \mathrm{~h}$ of GA treatment, cell motility decreased to $27.5,11.7$ and $9.2 \%$ respectively. Bars, SD. carcinomas, as a result of which cell growth rate is higher and local invasion is increased $(25,26)$. Degradation of HER2 protein following GA treatment has been observed in many human carcinomas, including melanoma, ovarian and breast cancer $(5,27,28)$. In this study we found that GA destablizes HER2 protein in a dose-dependent manner in a HER2overexpressing human breast cancer cell line SKBr3. We also found that proliferation was decreased in a dosedependent manner, consistent with previous studies $(5,13$, 28-31). Since the biological activity of overexpressed HER2 protein in breast cancer cells remains unclear, interest in identifying a mechanism by which GA-mediated HER2 degradation inhibits breast cancer cell proliferation has received much attention in recent years. Several signaling pathways have been found to be involved in this process, including the phosphatidylinositol 3'-Kinase-AKT-dependent pathway $(13,32)$ and the $\mathrm{Wnt} / \mathrm{B}$-catenin signaling pathway (5). In this study we extend these studies and provide evidence that HER2 degradation-dependent repression of Wnt/ß-catenin signaling can account for some of the anticancer effects of GA treatment on breast cancer cells.

Ectopic activation of $\mathrm{Wnt} / \mathrm{B}$-catenin signaling pathway has been observed in SKBr3 breast cancer cell line (14), so this cell line naturally became the ideal model for research of a 
functional relationship between HER2 tyrosine kinase and Wnt/ß-catenin signaling pathway. $\beta$-catenin regulates transcription of Wnt signaling targets in concert with TCF/LEF proteins. The transcriptional activity of $\beta$-catenin is regulated by its subcellular location $(6,7)$. After GA treatment, the amount of nuclear B-catenin decreased to about $20 \%$ of that in untreated cells, while the association between $\beta$-catenin and E-cadherin was greatly enhanced. These data suggest that GA treatment and HER2 degradation can switch the activity of $\beta$-catenin from transcription to cell-cell adhesion, both of which have implication for tumorigenicity. Decreased nuclear $\beta$-catenin leads to decreased expression of the cell cycle-promoting gene cyclin D1, whereas increased E-cadherinassociated $B$-catenin leads to decreased motility. These two key features of tumorigenicity are discussed next.

Cyclin D1 is an essential G1 cyclin, and is involved in regulating the G1-S transition. Overexpression of cyclin D1 in cultured cells promotes rapid progression from $\mathrm{G} 1$ to $\mathrm{S}$ phase and increases cell proliferation (33). Cyclin D1 was first shown to be downstream of HER2-mediated transformation in tissue culture models. In vivo, cyclin D1 deficient mice are completely resistant to HER2-mediated mammary tumorigenesis (34). Together, these findings suggest that cyclin D1 is downstream of, and required for, the HER2mediated tumorigenesis. Cyclin D1 is a major transcriptional target gene of $\mathrm{Wnt} / \mathrm{B}$-catenin signaling pathway, providing evidence for a link between HER2 and Wnt/ß-catenin signaling. Moreover, recent studies have shown that approximately $40 \%$ of breast cancers overexpress cyclin D1 and almost of all of these $(92 \%)$ also had high levels of active B-catenin (35). These observations strongly suggest that overexpression of cyclin D1 in HER2-mediated mammary tumorigenesis is a result of ectopic activation of Wnt/ß-catenin signaling pathway. In this study we observed a correlation between HER 2 and nuclear ß-catenin levels and proliferation, following GA treatment. Moreover, cell cycle analysis showed that GA treatment also leads to a dose-dependent G1 arrest, and that this G1 block is associated with a reduction in cyclin D1 expression, thereby providing a mechanism by which GA inhibits growth of a HER2-overexpressing breast cancer cell line.

In addition to preventing proliferation, GA treatment may also exert its anti-tumorigenic effects by reducing the motility of SKBr3 cells. The E-cadherin- $\beta$-catenin complex plays an essential role in adhesion of normal breast tissue. Disruption of this complex is thought to result in reduced cell-cell adhesion increased invasiveness, without affecting levels of E-cadherin (21). In this study, GA treatment reduced cell motility while increasing levels of the E-cadherin- $\beta$-catenin complex. Notably, the amount of E-cadherin remained unchanged before and after GA treatment. These observations strongly support the proposal that GA could reduce the invasiveness of breast cancer cells that, like SKBr3 cells, express high levels of HER2 protein by promoting degradation of HER2 protein and thereby enhancing binding between Ecadherin and $\beta$-catenin.

In conclusion, $G A$ reduces the tumorigenicity of the HER2-overexpressing breast cancer cell line SKBr3, at least in part by destabilizing the HER 2 oncoprotein, and disruption of the functional relationship between HER2 and the Wnt/ ß-catenin signaling pathway. Our findings provide evidence to support the clinical utility of GA in treatment of HER2 overexpressing breast cancer patients.

\section{References}

1. Pegram MD, Pauletti G and Slamon DJ: HER-2/neu as a predictive marker of response to breast cancer therapy. Breast Cancer Res Treat 52: 65-77, 1998.

2. Nabholtz JM, Reese DM and Lindsay MA: HER2-positive breast cancer: update on breast cancer international research group trials. Clin Breast Cancer 3: S75-S79, 2002.

3. Pellikainen J, Naukkarinen A, Ropponen K, Rummukainen J, Kataja V, Kellokoski J, Eskelinen M and Kosma VM: Expression of HER2 and its association with AP-2 in breast cancer. Eur J Cancer 40: 1485-1495, 2004.

4. Carter WB, Hoying JB, Boswell C and Williams SK: HER2/neu overexpression induces endothelial cell retraction. Int J Cancer 91: 295-299, 2001.

5. Bonvini P, An WG, Rosolen A, Nguyen P, Trepel J, Garcia de Herreros A, Dunach M and Neckers LM: Geldanamycin abrogates ErbB2 association with proteasome-resistant betacatenin in melanoma cells, increases beta-catenin-E-cadherin association, and decreases beta-catenin-sensitive transcription. Cancer Res 61: 1671-1677, 2001.

6. Akiyama T: Wnt/ß-catenin signaling. Cytokine Growth Factor Rev 11: 273-282, 2000.

7. Giles RH, van Es JH and Clevers H: Caught up in a Wnt storm: Wnt signaling in cancer. Biochimica Biophysica Acta 1653: 1-24, 2003.

8. Shibata T, Ochiai A, Kanai Y, Akimoto S, Gotoh M, Yasui N, Machinami R and Hirohashi S: Dominant negative inhibition of the association between $B$-catenin and c-erbB- 2 by $N$-terminally deleted $\beta$-catenin suppresses the invasion and metastasis of cancer cells. Oncogene 13: 883-889, 1996.

9. Roura S, Miravet S, Piedra J, Garcia de Herreros A and Dunach M: Regulation of E-cadherin/catenin association by tyrosine phosphorylation. J Biol Chem 17: 36734-36740, 1999.

10. Stebbins CE, Russo AA, Schneider C, Rosen N, Hartl FU and Pavletich NP: Crystal structure of an Hsp90-geldanamycin complex: targeting of a protein chaperone by an antitumor agent. Cell 89: 239-250, 1997.

11. Prodromou C, Roe SM, O'Brien R, Ladbury JE, Piper PW and Pearl LH: Identification and structural characterization of the ATP/ADP-binding site in the Hsp90 molecular chaperone. Cell 90: 65-75, 1997.

12. Neckers L: Hsp90 inhibitors as novel cancer chemotherapeutic agents. Trends Mol Med 8: S55-S61, 2002.

13. Munster PN, Marchion DC, Basso AD and Rosen N: Degradation of HER2 by ansamycins induces growth arrest and apoptosis in cells with HER2 overexpression via a HER3, phosphatidylinositol 3'-kinase-AKT-dependent pathway. Cancer Res 62: 3132-3137, 2002.

14. Mhashilkar AM, Stewart AL, Sieger K, Yang HY, Khimani AH, Ito I, Saito Y, Hunt KK, Grimm EA, Roth JA, Meyn RE, Ramesh $\mathrm{R}$ and Chada S: MDA-7 negatively regulates the $B$ catenin and PI3K signaling pathways in breast and lung tumor cells. Mol Ther 8: 207-219, 2003.

15. Schroeder JA, Thompson MC, Gardner MM and Gendler SJ: Transgenic MUC1 interacts with Epidermal growth factor receptor and correlates with mitogen-activated protein kinase activation in the mouse mammary gland. J Biol Chem 276: 13057-13064, 2001

16. Nusse M, Beisker W, Hoffmann C and Tarnok A: Flow cytometric analysis of G1- and G2/M-phase subpolulations in mammalian cell nuclei using side scatter and DNA content measurement. Cytometry 11: 813-821, 1990.

17. Austin CD, De Maziere AM, Pisacane PI, van Dijk SM, Eigenbrot C, Sliwkowski MX, Klumperman J and Scheller RH: Endocytosis and sorting of ErbB2 and the site of action of cancer therapeutic trastuzumab and geldanamycin. Mol Biol Cell 15: 5268-5282, 2004.

18. Elegbede JA, Flores R and Robert C: Perillyl alcohol and perillaldehyde induced cell cycle arrest and cell death in BroTo and A549 cells cultured in vitro. Life Sci 73: 2831-2840, 2003.

19. Schroeder JA, Adriance MC, McConnell EJ, Thompson MC, Pockaj B and Gendler SJ: ErbB-beta-catenin complexes are associated with human infiltrating ductal breast and murine mammary tumor virus (MMTV)-Wnt-1 and MMTV-c-Neu transgenic carcinomas. J Biol Chem 277: 22692-22698, 2002. 
20. Blenz M: ß-catenin: a pivot between cell adhesion and Wnt signaling. Curr Biol 15: R64-R67, 2004.

21. Jiang WG and Mansel RE: E-cadherin complex and its abnormalities in human breast cancer. Surg Oncol 9: 151-171, 2000.

22. Srethapakdi M, Liu F, Tavorath R and Rosen N: Inhibition of Hsp90 function by ansamycins causes retinoblastoma gene product-dependent G1 arrest. Cancer Res 60: 3940-3946, 2000.

23. Chiosis G, Timaul MN, Lucas B, Munster PN, Zheng FF, Sepp-Lorenzino L and Rosen N: A small molecule designed to bind to the adenine nucleotide pocket of Hsp90 causes Her2 degradation and the growth arrest and differentiation of breast cancer cells. Chem Biol 8: 289-299, 2001.

24. Muller T, Choidas A, Reichmann E and Ullrich A: Phosphorylation and free pool of beta-catenin are regulated by tyrosine kinases and tyrosine phosphatases during epithelial cell migration J Biol Chem 274: 10173-10183, 1999.

25. Ménard S, Balsari A, Casalini P, Tagliabue E, Campiglio M, Bufalino R and Cascinelli N: HER2-positive breast carcinomas as a particular subset with peculiar clinical behaviors. Clin Cancer Res 8: 520-525, 2002.

26. Van't Veer LJ, Dai H, van de Vijver MJ, He YD, Hart AA, Mao M, Peterse HL, van der Kooy K, Marton MJ, Witteveen AT, Schreiber GJ, Kerkhoven RM, Roberts C, Linsley PS, Bernards R and Friend SH: Gene expression profiling predicts clinical outcome of breast cancer. Nature 415: 530-536, 2002.

27. Smith V, Hobbs S, Court W, Eccles S, Workman P and Kelland LR: ErbB2 overexpression in an ovarian cancer cell line confers sensitivity to the HSP90 inhibitor geldanamycin. Anticancer Res 22: 1993-1999, 2002.

28. Xu W, Mimnaugh E, Rosser MF, Nicchitta C, Marcu M, Yarden Y and Neckers L: Sensitivity of mature ErbB2 to geldanamycin is conferred by its kinase domain and is mediated by the chaperone protein Hsp90. J Biol Chem 276: 3702-3708, 2001.
29. Chiosis G, Lucas B, Shtil A, Huezo H and Rosen N: Development of a purine-scaffold novel class of Hsp90 binders that inhibit the proliferation of cancer cells and induce the degradation of Her2 tyrosine kinase. Bioorg Med Chem 10: 3555-3564, 2001

30. Citri A, Alroy I, Lavi S, Rubin C, Xu W, Grammatikakis N, Patterson C, Neckers L, Fry DW and Yarden Y: Drug-induced ubiquitylation and degradation of ErbB receptor tyrosine kinases: implications for cancer therapy. EMBO J 21: 2407-2417, 2002.

31. Tikhomirov $\mathrm{O}$ and Carpenter G: Caspase-dependent cleavage of ErbB-2 by geldanamycin and staurosporin. J Biol Chem 276: 33675-33680, 2001.

32. Xu W, Yuan X, Jung YJ, Yang Y, Basso A, Rosen N, Chung EJ, Trepel $J$ and Neckers L: The heat shock protein 90 inhibitor geldanamycin and the ErbB inhibitor ZD1839 promote rapid PP1 phosphatase-dependent inactivation of AKT in ErbB2 overexpressing breast cancer cells. Cancer Res 63: 7777-7784, 2003.

33. Sugimachi K, Aishima S, Taguchi K, Tanaka S, Shimada M, Kajiyama K, Sugimachi K and Tsuneyoshi M: The role of overexpression and gene amplification of cyclin D1 in intrahepatic cholangiocarcinoma. J Hepatol 35: 74-79, 2001.

34. Yu Q, Geng Y and Sicinski P: Specific protection against breast cancers by cyclin D1 ablation. Nature 411: 1017-1021, 2001.

35. Miyoshi K and Hennighausen L: B-catenin: a transforming factor on many stages. Breast Cancer Res 5: 63-68, 2003. 